\title{
Correction to: Assessing climate change impacts on water resources in the Benue River Basin, Northern Cameroon
}

\author{
Rodric M. Nonki ${ }^{1} \cdot$ André Lenouo $^{2} \cdot$ Christopher J. Lennard $^{3} \cdot$ Clément Tchawoua $^{4}$
}

Published online: 27 February 2020

c) Springer-Verlag GmbH Germany, part of Springer Nature 2020

\section{Correction to: Environmental Earth Sciences (2019) 78 https://doi.org/10.1007/s12665-019-8614-4}

The original article has been published inadvertently with some errors in Fig. 1 legend and we have also missing a reference of that figure. The corrected legend of Fig. 1 is given below.

Fig. 1 Study area: basin localization (a), basin drainage area (b) (source: Dassou, 2019)
And the reference is:

Dassou EF (2019) Impact of climate variability on the hydrological response of the Upper Benue watershed (North Cameroon). Ph.D thesis, University of Maroua, Cameroon

Publisher's Note Springer Nature remains neutral with regard to jurisdictional claims in published maps and institutional affiliations.

The original article can be found online at https://doi.org/10.1007/ s12665-019-8614-4.

Rodric M. Nonki

norome31@yahoo.fr

$1 \quad$ Laboratory for Environmental Modeling and Atmospheric Physics (LEMAP), Department of Physics, Faculty of Sciences, University of Yaounde I, Yaoundé, Cameroon

2 Department of Physics, Faculty of Science, University of Douala, Douala, Cameroon

3 Climate System Analysis Group, University of Cape Town, Cape Town, South Africa

4 Laboratory of Mechanics, Department of Physics, Faculty of Sciences, University of Yaounde I, Yaoundé, Cameroon 